\title{
Radiodensitometric and DXA analyses for the measurement of bone mineral density after systemic alendronate therapy
}

\section{Marília Pacífico Lucisano(a) \\ Paulo Nelson-Filho(a) \\ Leslie Morse ${ }^{(b)}$ \\ Ricardo Battaglino(c) \\ Plauto Christopher Aranha \\ Watanabe ${ }^{(d)}$ \\ Raquel Assed Bezerra da Silva ${ }^{(a)}$ \\ Lea Assed Bezerra da Silva(a)}

\footnotetext{
(a) Department of Pediatric Clinics, Preventive and Community Dentistry, School of Dentistry of Ribeirão Preto, Univ de São Paulo - USP, Ribeirão Preto, SP, Brazil.

(b) Department of Physical Medicine and Rehabilitation, School of Medicine, Harvard Univ, Boston, MA, USA.

(c) Department of Skeletal Biology, Forsyth Institute, Cambridge, MA, USA.

(d) Department of Morphology, Stomatology and Physiology, School of Dentistry of Ribeirão Preto, Univ de São Paulo - USP, Ribeirão Preto, SP, Brazil.
}

\begin{abstract}
Precise techniques for the measurement of maxillary bone mineral density (BMD) are useful for the early diagnosis of systemic diseases. The aim of this study was to compare in vivo the efficacy of dualenergy x-ray absorptiometry (DXA) and radiographic densitometry for the measurement of BMD after systemic administration of sodium alendronate. Wistar rats were randomly allocated to a control group $(\mathrm{n}=5)$, which received distilled water, and a sodium alendronate group $(\mathrm{n}=8)$, which received two doses of chemically pure sodium alendronate $(1 \mathrm{mg} /$ $\mathrm{kg}$ ) per week. After 8 weeks, the animals were euthanized, the tibias were removed, and the BMD of the proximal tibial metaphysis was analyzed radiographically and by DXA. The data were subjected to statistical analysis by the Kruskal-Wallis test at a significance level of 5\%. Both of the techniques revealed that the alendronate-treated group had a significantly higher BMD $(\mathrm{p}<0.05)$ than the control group after 8 weeks of treatment. Comparing the groups with and without alendronate therapy revealed increases of $14.9 \%$ and $29.6 \%$ in $\mathrm{BMD}$, as detected radiographically and by DXA, respectively. In conclusion, both of the methods were able to detect an increase in BMD of the proximal tibial metaphysis after alendronate therapy.
\end{abstract}

Descriptors: Bone Density; Alendronate; Bone Remodeling.

\section{Introduction}

Osteometabolic disorders have recently been the subject of extensive

Declaration of Interests: The authors certify that they have no commercial or associative interest that represents a conflict of interest in connection with the manuscript.

Corresponding Author:

Paulo Nelson-Filho

E-mail:nelson@forp.usp.br

Submitted: Sep 27, 2012

Accepted for publication: Feb 04, 2013

Last revision: Feb 18, 2013 research in the field of bone biology. Special attention has been directed towards osteoporosis, which is one of the major health problems that affects postmenopausal women due to decreased estrogen levels secondary to the loss of ovarian function. ${ }^{1,2}$ The trabecular bone is compromised as a result of excessive resorption, ${ }^{3}$ and bone mass is reduced, thus increasing bone fragility and the risk of fractures. ${ }^{4}$

The complications of osteoporosis and other bone disorders may be prevented by early detection of the pathology ${ }^{1}$ and establishment of an adequate therapy, which justifies the large number of experiments addressing disease progression and drug efficacy. Several studies have suggested a relationship between osteoporosis and oral diseases and have emphasized the potential utility of dentists issuing early warnings about 


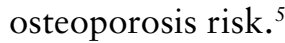

The mineral density of long bones is widely used to evaluate alterations in the balance between osteoblastic bone formation and osteoclastic bone resorption, which could be suggestive of bone disorders. ${ }^{6}$ Bone densitometry facilitates the early diagnosis of metabolic bone diseases associated with intense bone resorption, such as osteopenic and osteoporotic conditions, and this method can be used to monitor treatment efficacy, thereby significantly decreasing the incidence of pathological fractures. ${ }^{7}$

Some non-invasive imaging technologies, such as magnetic resonance imaging (MRI), ultrasound, computed tomography (CT), dual-energy x-ray absorptiometry (DXA) ${ }^{8}$ and radiographic densitometry, ${ }^{1}$ have been employed in medical diagnosis for different purposes. Furthermore, periapical and panoramic radiography techniques, which are commonly used in dental practice, could also be useful for the detection of bone disorders.

DXA is currently the most widely applied method used to evaluate bone mineral density (BMD) and bone mineral content (BMC) in a highly accurate, rapid and effective manner. ${ }^{6,9-13}$ However, due to the limited availability and cost implications of DXA devices in some regions, the diagnosis of bone disorders may be delayed until the clinical symptoms appear. ${ }^{1}$ Therefore, the use of alternative methods, such as radiographic densitometry, would facilitate patient access to early diagnosis of osteometabolic diseases and broaden the opportunities for animal studies, which could contribute to advances in the field of bone biology.

Bisphosphonates are the major class of drugs that are currently employed in the treatment of osteoporosis and a number of other diseases characterized by increased bone resorption due to osteoclastic activity. ${ }^{14}$ Sodium alendronate belongs to the subgroup of nitrogen-containing bisphosphonates; it acts as a potent, specific inhibitor of osteoclast-mediated bone resorption and increases BMD. ${ }^{15}$

Therefore, the purpose of this study was to compare, in vivo, the efficacy of DXA and radiographic densitometry for measuring BMD after systemic administration of sodium alendronate. The hypothesis tested was that both the DXA and radiographic den- sitometry techniques could be similarly useful in the evaluation of BMD, and hence, dentists could play an important role in the early detection of systemic bone diseases.

\section{Methodology}

Thirteen male Wistar rats (Rattus norvegicus albinus) (36 to 42 days old) weighing 200 to $230 \mathrm{~g}$ were selected for use after the study was approved by the institutional Ethics Committee for Animal Care and Research Use (Protocol number 10.1.468.53.5). The animals were housed in cages with natural lighting and a mean temperature of $24^{\circ} \mathrm{C} \pm 0.5^{\circ} \mathrm{C}$, and they were fed standard rat chow and water $a d$ libitum during the entire experimental period.

The experimental design was the same as that described previously in the first part of this study. ${ }^{11}$ In the study, 5 animals (a total of 10 tibias) were included in the control group, which received distilled water, and 8 animals (a total of 15 tibias; 1 tibia was fractured during extraction) were included in the sodium alendronate group, which received chemically pure sodium alendronate (Alendronate Monosodium Trihydrate; Galena Química e Farmacêutica Ltda., Campinas, Brazil) at a dose of $1 \mathrm{mg} / \mathrm{kg}$ body weight diluted in distilled water. Because the metabolic rate in rats is twice as fast as that in humans, as described in the study of Nelson-Filho et al. ${ }^{11}$, the drug was administered twice per week (on Tuesdays and Fridays) during the same period of the day to achieve a dose comparable to that given to human patients ( $1 \mathrm{mg} / \mathrm{kg}$ body weight once per week). A volume of $0.3 \mathrm{~mL}$ was administered on each day by gavage. A 3-cm-long silicone gastrointestinal tube (\#6 Levin tube) (Mark Med Indústria e Comércio Ltda., Bragança Paulista, Brazil) coupled with a disposable $1 \mathrm{~mL}$ syringe (Insulina Injex, Injex Indústrias Cirúrgicas Ltda., Ourinhos, Brazil) was used to inject the solution directly into the gastrointestinal tract. The control animals received only distilled water by the same route of administration. The treatment duration was 8 weeks for both of the groups. The animals were weighed every week on an electronic analytical balance (Model 3400, Toledo do Brasil Ind. de Balanças Ltda., Toledo, Brazil) so that the dose of sodium alendronate solution 
could be adjusted according to the body weight of each animal.

The rats were killed after 8 weeks of treatment with a lethal injection of a mixture of ketamine hydrochloride (Ketamina Agener ${ }^{\circledR}$, União Química Farmaêutica Nacional S/A, Embu-Guaçu, Brazil; $300 \mathrm{mg} / \mathrm{mL}$ ) and xylazine hydrochloride $\left(\right.$ Dopaser $^{\circledR}$; Caleir S.A., Barcelona, Spain; 30 mg/mL). The tibias were surgically removed, and the BMD was evaluated by radiographic densitometry and DXA.

\section{BMD analysis by radiographic densitometry}

The freshly removed tibias from both of the groups were dissected, cleaned and frozen at $-20^{\circ} \mathrm{C}$. The sodium alendronate $(\mathrm{n}=15)$ and control $(\mathrm{n}=10)$ tibias were arranged symmetrically on extraoral radiographic films (Kodak ${ }^{\circledR}$ Min-R S, Kodak Eastman Co., Rochester, USA) together with an aluminum stepwedge with 8 steps (NDT Mart Inc., Covington, USA), ranging from 2 to $16 \mathrm{~mm}$, which served as a reference for densitometric analysis. Radiographic densitometry was performed based on the studies by Issa et al. ${ }^{7}$ and Erdogan et al. ${ }^{1}$ The tube of the x-ray unit (Weber x-ray unit; The Weber Dental Mfg. Co., Canton, USA) was placed perpendicular to the film, and a single radiographic exposure was made with exposure parameters of $10 \mathrm{~mA}$, $60 \mathrm{kV}, 0.6$ seconds and $40 \mathrm{~cm}$ focus-film distance. Radiographic processing was performed for $2 \mathrm{~min}$ utes in the developing solution $\left(27^{\circ} \mathrm{C}\right), 30 \mathrm{~s}$ in the intermediate phase, 4 minutes in the fixer solution, and 10 minutes in the final rinse. All of these factors were monitored using a Victodreen NERO 6000B (Non-Invasive Evaluator Radiation Outputs, Modelo 6000B, Victoreen Inc., Everett, USA).

Three radiographs were obtained, digitized with a professional flatbed scanner (Expression 636, Epson Ltd., Long Beach, USA) and then saved in the TIFF format. The resolution and bits of the scanned images were 600 pixels/inch or 23,622 pixels $/ \mathrm{cm}$. Each image was analyzed using the histogram of the intensity of the tone scales in the "light channel" of Adobe Photoshop 7.0.1 image-editing software (Adobe Systems Incorporated, San Jose, USA). The area that was selected to obtain the mean value of light intensity was the proximal tibial metaphysis, as in most of the bone biology studies. ${ }^{8,16,17}$ The values that were obtained from each step of the aluminum stepwedge were used to calibrate the software and as references for the sample values. After three radiographs were obtained of each specimen, a mean BMD value was calculated for each group (sodium alendronate group and control group).

\section{BMD analysis by DXA}

After radiographic analysis of bone density, the samples were placed in Falcon tubes (Techno Plastic Products AG, Transadingen, Switzerland) with lids containing phosphate buffer saline, and the BMD of the proximal tibial metaphysis was analyzed by a dual-energy x-ray densitometer (Dual Lunar PIXImus; PIXImus Corp. Headquarters, Madison, USA) at the Department of Skeletal Biology of The Forsyth Institute, Cambridge, USA. The tibias were examined with DXA to record the BMD in $\mathrm{g} / \mathrm{cm}^{2}$. Data were analyzed using the manufacturer-supplied software Lunar PIXImus, version 2.2 (Lunar PIXImus Corp. Headquarters, Madison, USA).

\section{Statistical analysis}

Radiographic densitometry and DXA data were statistically analyzed by the Kruskal-Wallis test at a $5 \%$ significance level using the SAS (Statistical Analysis System) software for Windows version 9.1.3 (SAS Institute Inc., Cary, USA).

\section{Results}

The animals in both of the groups showed a similar pattern of gradual weight gain during the experiment (data not shown), which indicates that alendronate administration did not affect growth.

Figures 1 and 2 present the BMD values of proximal tibial metaphysis obtained by radiographic densitometry and DXA in the sodium alendronate and control groups, respectively, after 8 weeks of treatment. In Table 1 , the results obtained with both of the methods are compared between the 2 groups.

Both the radiodensitometric and DXA analyses revealed that the sodium alendronate-treatment group had a significantly higher BMD $(\mathrm{p}<0.05)$ than the control group (distilled water) after 8 


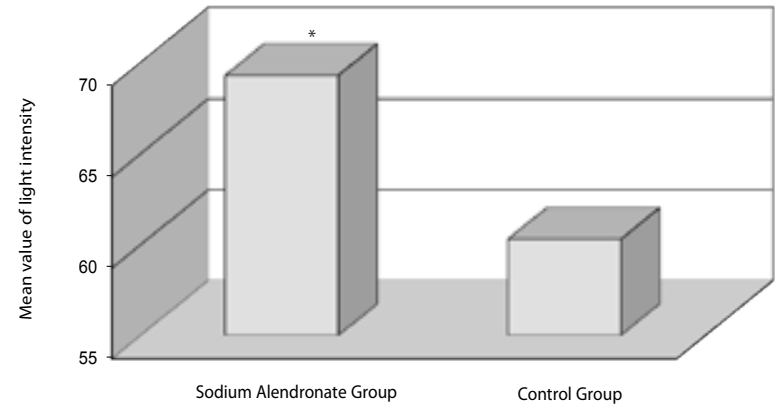

Figure 1 - Bone mineral density values of proximal tibial metaphysis (mean value of light intensity) that were obtained by radiographic densitometry in the sodium alendronate (administration of sodium alendronate) and control (administration of distilled water) groups. Asterisks indicate statistically significant differences.

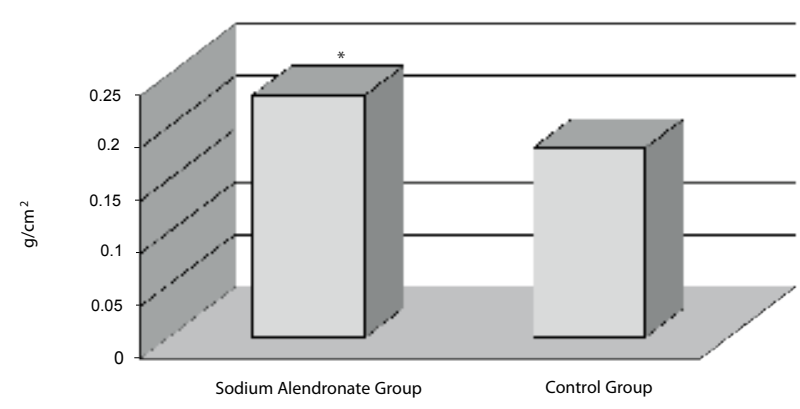

Figure 2 - Bone mineral density values of proximal tibial metaphysis $\left(\mathrm{g} / \mathrm{cm}^{2}\right)$ that were obtained by DXA in the sodium alendronate (administration of sodium alendronate) and control (administration of distilled water) groups. Asterisks indicate statistically significant differences.

\begin{abstract}
Table 1 - Comparison of bone mineral density values in the proximal tibial metaphysis that were obtained by radiographic densitometry and DXA $\left(\mathrm{g} / \mathrm{cm}^{2}\right)$ in the sodium alendronate (administration of sodium alendronate) and control (administration of distilled water) groups.

weeks of treatment. Comparing the groups with and without alendronate therapy revealed increases of $14.9 \%$ and $29.6 \%$ in BMD, as determined using radiographic densitometry and DXA, respectively. Briefly, these results showed that when the DXA technique is inaccessible, radiographic densitometry is a valid method to detect alterations in the balance between bone formation and bone resorption.
\end{abstract}

* $p$ value for the Kruskal-Wallis test; M: median; Q1: first quartile; Q3: third quartile.

\begin{tabular}{|c|c|c|c|}
\hline \multirow[t]{2}{*}{ Method } & $\begin{array}{l}\text { Sodium alendronate group } \\
\qquad(\mathrm{n}=15)\end{array}$ & $\begin{array}{l}\text { Control group } \\
(n=10)\end{array}$ & \multirow[t]{2}{*}{$p$ value } \\
\hline & $M(Q 1-Q 3)$ & $M(Q 1-Q 3)$ & \\
\hline $\begin{array}{l}\text { Radiographic } \\
\text { densitometry }\end{array}$ & $66.8(64.1-72.6)$ & $60.5(57.9-62.8)$ & 0.0010 \\
\hline DXA & $0.230(0.197-0.252)$ & $0.181(0.176-0.185)$ & 0.0001 \\
\hline
\end{tabular}

\section{Discussion}

Sodium alendronate, which is a nitrogen-containing bisphosphonate, enters the mature osteoclasts and inhibits the synthesis of farnesyl pyrophosphate synthase, an enzyme of the mevalonate pathway. As a result, a cascade of events is initiated that causes toxic effects on the osteoclasts, including suppression of resorptive activity, loss of cytoskeletal integrity and ruffled borders and, ultimately, apoptotic cell death. ${ }^{14}$ Briefly, sodium alendronate acts as a potent, specific inhibitor of osteoclast-mediated bone remodeling and increases bone mineral density.

Bone densitometry is commonly used in medicine to measure BMD, ${ }^{7}$ and it is an important method for the early diagnosis of osteopenic and osteoporotic conditions, as well as for monitoring treatment evolution. ${ }^{18}$ In addition to radiographic densitometry, the contemporary methods of bone densitometry include single-photon absorptiometry, single-energy x-ray absorptiometry, dual-photon absorptiometry and DXA. ${ }^{7}$

The measurement of BMD in long bones or the spine by DXA is currently recognized as a well-established method for the diagnosis of osteoporosis. ${ }^{10}$ The operation of DXA devices is based on the principle that the bone and soft tissue have different attenuation properties as a function of photon energy. Therefore, DXA uses an x-ray source to produce a discrete energy beam that is attenuated as it travels through the patient. ${ }^{9,19}$ In the present study, DXA was highly effective in measuring the BMD of rat proximal tibial metaphysis and revealed a signifi- 
cant difference between the 2 groups, with an almost $30 \%$ increase in BMD in the animals that were subjected to alendronate therapy for 8 weeks.

DXA has recently been adapted to measure body composition in animals, such as rats and mice, using specialized software in conjunction with clinical whole-body DXA machines. ${ }^{20}$ The Lunar PIXImus used in the present study is a fully integrated densitometer with an attached laptop computer and desktop printer; it was designed for the estimation of BMD and body composition. The Lunar PIXImus stands out as an effective DXA device for measuring BMD in small lab animals for bone biology research. ${ }^{21-23}$

The measurement of BMD in long bones by DXA could be useful to predict BMD of the mandibular body. Changes in the metabolism of bone tissue in the jaw region seem to be similar to those observed in long bones because both of these bones are subjected to strenuous muscle activity. ${ }^{24}$

Radiographic analysis is an important adjunctive tool for clinical evaluation because it is a rapid, non-invasive and low-cost method ${ }^{4}$ and can produce results similar to those of histological studies. ${ }^{25}$ The measurement of BMD by radiographic densitometry has been performed in a number of studies, and its efficacy has been confirmed. ., $, 7,26$ Radiographic densitometry may be considered as a minimally invasive and convenient method for diagnosing osteoporosis. ${ }^{1}$ According to Erdogan et al., ${ }^{1}$ the radiological parameters can facilitate the establishment of a definite diagnosis of osteoporosis.

In the present study, radiographic densitometry showed that the BMD values of proximal tibial metaphysis differed between the sodium alendronate and control groups. BMD was significantly higher in the tibias of rats that were treated with sodium alendronate compared to those that received distilled water. Comparing the two groups revealed in-

\section{References}

1. Erdogan O, Incki KK, Benlidayi ME, Seydaoglu G, Kelekci S. Dental and radiographic findings as predictors of osteoporosis in postmenopausal women. Geriatr Gerontol Int. 2009 Jun;9(2):155-64. creases of $14.9 \%$ and $29.6 \%$ in $\mathrm{BMD}$, as determined by radiographic densitometry and DXA, respectively. Although a higher percentage increase in BMD was determined by DXA, the results of the present study showed that radiographic densitometry is also an effective, accurate and safe method for measuring the BMD of long bones. Similarly, according to Griffith et al. ${ }^{27}$, although radiographic densitometry may not be the most sensitive method of measuring bone density, it is nevertheless a readily available, though widely underused, determinant of bone quality. Furthermore, radiographic assessment is commonly used in everyday clinical practice. ${ }^{28}$

Because radiographic densitometry is more readily available to health professionals and more accessible to the population due to its lower cost, this technique is useful for the early diagnosis of osteometabolic disorders, especially osteoporosis, which allows for the establishment of an adequate treatment strategy and improves the prognosis of these pathologies. Additionally, the use of radiographic densitometry could increase the number of studies in the field of bone biology, thus contributing to advances in the diagnosis, treatment and monitoring of bone diseases, which would increase the life quality and life expectancy of patients.

\section{Conclusion}

Based on the results of this study, it may be concluded that both of the methods were effective in detecting an increase in the BMD of the proximal tibial metaphysis after systemic administration of sodium alendronate for 8 weeks. Additionally, the results suggest that when DXA is not available, radiographic densitometry may be used as an auxiliary method in humans in the field of bone biology to evaluate the balance between bone formation and bone resorption.

2. Consensus Development Conference on Osteopororsis. Am J Med. 1993 Nov;95(5A):5S-16S.

3. Friedlander AH. The physiology, medical management and oral implications of menopause. J Am Dent Assoc. 2002 Jan;133(1):73-81. 
4. Giro G, Gonçalves D, Sakakura CE, Pereira RMR, Marcantonio Jr E, Orrico SRP. Influency of estrogen deficiency and its treatment with alendronate and estrogen on bone density around osseointegrated implants: radiographic study in female rats. Oral Surg Oral Med Oral Pathol Oral Radiol Endod. 2008 Feb;105(2):162-7.

5. Martínez-Maestre MA, González-Cejudo C, Machuca G, Torrejón R, Castelo-Branco C. Periodontitis and osteoporosis: a systematic review. Climacteric. 2010 Dec;13(6):523-9.

6. Lochmüller EM, Jung V, Weusten A, Wehr U, Wolf E, Eckstein F. Precision of high-resolution dual energy X-ray absorptiometry of bone mineral status and body composition in small animal models. Eur Cell Mater. 2001 Jan 20;1:43-51.

7. Issa JPM, Tiossi R, Watanabe PCA, Siéssere S, Regalo SCH, Lopes RA, et al. Newly formed bone in mandible decortication experimental model using rhBMP-2 evaluated by densitometric study. Int J Morphol. 2008;26(1):83-8.

8. Breen SA, Loveday BE, Millest AJ, Waterton JC. Stimulation and inhibition of bone formation: use of peripheral quantitative computed tomography in the mouse in vivo. Lab Anim. 1998 Oct;32(4):467-76.

9. Devlin H, Horner K, Ledgerton D. A comparison of maxillary and mandibular bone mineral densities. J Prosthet Dent. 1998 Mar;79(3):323-7.

10. Lane NE. Epidemiology, etiology, and diagnosis of osteoporosis. Am J Obstet Gynecol. 2006 Feb;194(2 Suppl):S3-11.

11. Nelson-Filho P, Lucisano MP, Silva RAB, Silva RS, Serra MC, Gerlach RF, et al. Systemically alendronate was incorporated into dental tissues but did not cause morphological or mechanical changes in rats teeth. Microsc Res Tech. 2012 Sep;75(9):1265-71. Epub 2012 Apr 17.

12. Gondim V, Aun J, Fukuda CT, Takayama L, Latorre MD, Pannuti CM, et al. Severe loss of clinical attachment level: an independent association with low hip bone mineral density in postmenopausal females. J Periodontol. 2013 Mar;84(3):3529. Epub 2012 May 1.

13. Aboelasrar MA, Elbarbary NS, Elshennawy DE, Omar AM. Insulin-like growth factor-1 cytokines cross-talk in type 1 diabetes mellitus: relationship to microvascular complications and bone mineral density. Cytokine. 2012 Jul;59(1):86-93.

14. Russell RGG, Watts NB, Ebetino FH, Rogers MJ. Mechanisms of action of bisphosphonates: similarities and differences and their potential influence on clinical efficacy. Osteoporos Int. 2008 Jun;19(6):733-59.

15. Russell RGG, Xia Z, Dunford JE, Oppermann U, Kwaasi A, Hulley PA, et al. Bisphosphonates: an update on mechanisms of action and how these relate to clinical efficacy. Ann N Y Acad Sci. 2007 Nov;1117:209-57.

16. Schmidt C, Priemel M, Kohler T, Weusten A, Müller R, Amling $\mathrm{M}$, et al. Precision and accuracy of peripheral quantitative computed tomography (pQCT) in the mouse skeleton compared with histology and microcomputed tomography ( $\mu$ CT). J Bone Miner Res. 2003 Aug;18(8):1486-96.

17. Kanzaki S, Takada Y, Ogawa K, Matsuo K. Bisphosphonate therapy ameliorates hearing loss in mice lacking osteoprotegerin. J Bone Miner Res. 2009 Jan;24(1):43-9.

18. Lodder MC, Lems WF, Ader HJ, Marthinsen AE, van Coeverden SCCM, Lips P, et al. Reproducibility of bone mineral density measurement in daily practice. Ann Rheum Dis. 2004 Mar;63(3):285-9.

19. Hildebolt CF. Osteoporosis and oral bone loss. Dentomaxillofac Radiol. 1997 Jan;26(1):3-15.

20. Nagy TR, Clair AL. Precision and accuracy of dual-energy $\mathrm{X}$-ray absorptiometry for determining in vivo body composition of mice. Obes Res. 2000 Aug;8(5):392-8.

21. Bartell SM, Isales CM, Baile CA, Kuhar MJ, Hamrick MW. CART deficiency increases body weight but does not alter bone strength. J Musculoskelet Neuronal Interact. 2008 AprJun;89(2):146-53.

22. Earp JC, Dubois DC, Molano DS, Pyszczynski NA, Keller CE, Almon RR, et al. Modeling corticosteroid effects in a rat model of rheumatoid arthritis I: mechanistic disease progression model for the time course of collagen-induced arthritis in Lewis rats. J Pharmacol Exp Ther. 2008 Aug;326(2):532-45.

23. Katikaneni R, Ponnapakkam A, Miller E, Ponnapakkam T, Gensure RC. A new technique for precisely and accurately measuring lumbar spine bone mineral density in mice using clinical dual energy X-ray absorptiometry (DXA). Toxicol Mech Methods. 2009 Mar;19(3):225-31.

24. Buyukkaplan US, Guldag MU, Yildiz M, Gumus BA. Comparison of mandibular bone mineral density in osteoporotic, osteopenic and normal elderly edentulous subjects measured by the dual-energy X-ray absorptiometry technique. Gerodontology. 2012 Jun;29(2):e1098-102.

25. Sakakura CE, Margonar R, Holzhausen M, Nociti Jr FH, Alba Jr RC, Marcantonio Jr E. Influence of cyclosporin a therapy on bone healing around titanium implants: a histometric and biomechanic study in rabbits. J Periodontol. 2003 Jul;74(7):976-81.

26. Rowshan HH, Parham MA, Baur DA, McEntee RD, Cauley E, Carriere DT, et al. Effect of intermittent systemic administration of recombinant parathyroid hormone (1-34) on mandibular fracture healing in rats. J Oral Maxillofac Surg. 2010 Feb;68(2):260-7.

27. Griffith JF, Engelke K, Genant HK. Looking beyond bone mineral density: imaging assessment of bone quality. Ann $\mathrm{N}$ Y Acad Sci. 2010 Mar;1192:45-56.

28. Grados F, Fechtenbaum J, Flipon E, Kolta S, Roux C, Fardellone P. Radiographic methods for evaluating osteoporotic vertebral fractures. Joint Bone Spine. 2009 May;76(3):241-7. 